\title{
PLANOS DE INCENTIVOS BASEADOS EM OPÇÕES DE AÇÕES: UMA EXPOSIÇÃO DAS DISTINÇÕES ENCONTRADAS ENTRE AS DEMONSTRAÇÕES CONTÁBEIS ENVIADAS À CVM E À SEC
}

\author{
ALEXSSANDER DE ANTONIO NUNES \\ Mestre em Ciências Contábeis pela FACC/UFRJ - RJ \\ E-mail: alexnunes1@uol.com.br \\ JOSÉ AUGUSTO VEIGA DA COSTA MARQUES \\ Professor Doutor do Mestrado em Contabilidade da FACC/UFRJ - RJ \\ E-mail: joselaura@uol.com.br
}

\section{RESUMO}

Os planos de incentivos atrelados a opções de ações são uma forma de remuneração variável, na qual ao funcionário é dada a oportunidade de participar da empresa como acionista. Trata-se de um tipo de incentivo que pode apresentar vantagens para o funcionário e para a empresa. A Contabilidade trata da mensuração dos valores envolvidos e das formas de divulgação desses valores. Normas específicas constam no FASB e no IASB. No Brasil, a matéria é motivo de pareceres e recomendações da CVM e do IBRACON. Este artigo apresenta os fundamentos das opções de ações a funcionários e as normas existentes no tratamento contábil dos planos. No estudo empírico, foram selecionadas 14 companhias abertas nacionais e as informações coletadas demonstram que há diferenças entre o que é divulgado para os órgãos reguladores e o mercado de capitais brasileiro, em comparação à divulgação aos órgãos reguladores e ao mercado de capitais internacional.

Palavras-chave: Opções de Ações; Remuneração Variável; Contabilidade.

\begin{abstract}
Stock option plans are one form of variable compensation in which the employee is given the opportunity to participate in the company as a stockholder. This kind of stimulus can mean advantages for employees and companies. Accounting is responsible for measuring and disclosing the amounts involved. Both FASB and IASB present specific rules in this respect. In Brazil, this subject has been discussed in opinions and recommendations by CVM and IBRACON. This article presents the foundations of stock options for employees and existing rules for the accounting treatment of these plans. 14 national publicly-traded companies were selected for the empiric study. The collected information demonstrates that there are differences between what is disclosed to regulators and the capital market in Brazil and in the international context.
\end{abstract}

Keywords: Stock Options; Variable Compensation; Accounting. 


\section{INTRODUÇÃO}

Atualmente, sob vários motivos que fazem as empresas serem mais competitivas e buscarem cada vez mais a excelência em todos os seus processos, nota-se uma preocupação com a remuneração dos funcionários. Este trabalho, fruto da conclusão de dissertação de mestrado elaborada pelo autor, apresenta uma forma particular de remuneração variável, na qual o pagamento é associado à cessão de ações ou opções de ações. Os fundamentos da criação desses planos de incentivos podem ser explicados pela Teoria da Agência, que estuda a divisão entre a propriedade e a gestão dos recursos, e a geração potencial de conflitos devido a essa separação. Como meio para a redução dos conflitos, podem-se usar formas diferenciadas de remuneração, como as baseadas em títulos de propriedade.

O uso dessa forma de remuneração tem despertado, pelo menos nos últimos vinte anos, muito interesse no meio corporativo e já há algum tempo discussões envolvendo a mais acurada mensuração da despesa ocorrem no FASB e no IASB. Essa matéria, também, é pauta na CVM, onde atualmente não há regulamentação definitiva a respeito.

Como objetivo principal, este artigo se propõe a revelar as distinções encontradas entre as demonstrações contábeis apresentadas ao mercado de capitais local e ao mercado de capitais internacional. Como fases para se chegar ao objetivo principal, o estudo trata de verificar a existência de um método predominante de reconhecimento contábil e divulgação das transações que envolvem opções de ações a funcionários e apresentar as atuais discussões e entendimentos quanto ao tratamento desse tipo de incentivo.

A metodologia utilizada se baseia nos critérios descritivo e exploratório, com os procedimentos associados às pesquisas bibliográficas, documentais e ex post facto. Para este estudo foram selecionadas companhias abertas brasileiras listadas e ativas na CVM, usando de critérios não probabilísticos.

A pesquisa baseou-se, especificamente, nas atuais normas brasileiras e norte-americanas. Para enriquecimento do trabalho, também é exposta a atual regra do IASB, de publicação recente e que tende a tornar-se parâmetro nas mudanças que as outras entidades pretendem fazer nas suas normas.

\section{O QUE SÃO OS PLANOS DE INCENTIVOS BASEADOS EM OPÇÕES DE AÇÕES}

Antes de descrever o incentivo em particular, considerações serão feitas quanto às opções. A de- finição é simples e de fácil entendimento, conforme exposta a seguir:

Uma opção é um direito de comprar uma quantidade de ações numa data, ou após uma data, no futuro (data de exercício da opção), a um preço fixado na data em que a opção é oferecida [...] (BOVESPA, 2003 e ANTHONY e GOVINDARAJAN, 2002, p. 620).

Já quanto ao conceito de tais planos, ele consta da norma norte-americana que trata da contabilização das transações e do IBRACON como:

Tem-se um plano de incentivo a empregados baseado em opção por ações (Employee Stock options Plans - ESOP's) quando um seleto número dentro da totalidade do quadro de funcionários ganha a opção de compra de ações ordinárias a um preço fixo, e este preço de compra é estendido durante um espaço de tempo (SFAS n. 123, 1995).

Planos de opções de ações são aqueles em que o empregado tem direito de receber títulos de participação acionária emitidos pela Entidade (ou sua matriz); ou o valor da obrigação da Entidade para com o empregado condicionado ao valor futuro dos títulos de participação acionária emitidos pela Entidade (IBRACON apud CVM, 2000).

Os EUA são o país onde é mais difundido o conceito das opções de ações. Do mesmo modo, nele está concentrado o maior mercado de ações do mundo, mercado esse operado por um volume gigantesco de pequenos investidores, que nele depositam em grande proporção suas poupanças individuais (CHEN, 2003, p. 942). Mas não é somente lá que as opções para funcionários apresentaram crescimento de uso. Verifica-se que nos últimos anos, essa forma de remuneração teve grande crescimento em empresas situadas na Bélgica, Alemanha, Itália, Holanda e Espanha (NIEMANN e SIMONS, 2003, p. 321).

Quanto ao início de adoção de uso das opções como incentivo, o estudo de Smith e Wallace (1997, p. 460) demonstra que é antiga, amparada pela descrição da Chrysler Corporation que possui tal plano aprovado pelo Conselho de Administração em 1952 e, nos últimos vinte anos, houve um crescimento muito grande tanto no volume de empresas que adotaram tais planos quanto dos montantes envolvidos em cada empresa.

Conforme Catanach (2003, p. 386), os planos de opções de ações, exclusivos para executivos-sê- 
nior das grandes companhias, durante a década de 1990 tiveram um crescimento vultoso e acredita-se que mais de dez milhões de empregados, incluindo os de nível médio, possuem planos de opções de ações. Kraizberg, Tziner e Weisberg (2002, p. 384) citam um estudo de 1997 realizado pelo National Center for Employee Ownership (NCEO), entidade sem fins lucrativos que fornece informações confiáveis e objetivas sobre planos de opções em ações para funcionários e outros serviços relacionados, que indica entre 17 a 18 milhões de pessoas, nos EUA, beneficiários de planos de incentivos baseados em opções de ações, que as têm recebido num total de mais de US\$ 650 bilhões em ações, e que os planos existem em pelo menos dez mil empresas. Em nível percentual, o estudo de Arya e Sun (2004a, p. 30) detecta aumento do uso das opções de ações em empresas que possuem planos de incentivos de longo prazo. Conforme esses autores, o número das companhias cresceu de $32,9 \%$ para 46\%, durante o período de 1990 a 1996.

No Brasil a implantação de tais planos data da década de 1970, adotados pelas empresas norteamericanas instaladas no País, que praticamente importaram a mesma metodologia, para os executivos, aqui, locados. Nos últimos anos, verificou-se um crescimento muito grande na adoção desse tipo de incentivo, em que em empresas como a BristolMyers Squibb, eleita em 2000 pela revista Exame no anuário "Melhores e Maiores" a maior do setor farmacêutico e considerada pelo mesmo periódico como uma das "100 Melhores Empresas para se Trabalhar-2003", o oferecem a praticamente todos os funcionários (SILVEIRA, 2000, p. 48). No país, o dispositivo legal para a sua ocorrência é expresso no artigo 168, da Lei n. 6.404/76, que traz a possibilidade de remuneração dos funcionários ou prestadores de serviços através de planos de opções de ações.

O efetivo pagamento aos empregados pode ser feito pela entrega das próprias ações da companhia, em opções de ações ou outros títulos de participação, emitidos a favor dos empregados; ou em espécie, em que os valores estão atrelados ao valor de mercado das ações da companhia no futuro. Em todos os tipos, a recompensa depende de eventos futuros e, em quase todos, permanecer empregado é um elemento necessário para que o direito continue vigente (KIESO e WEYGANDT, 1998, p. 857).

Desse modo, à primeira vista constata-se que a maior vantagem para a empresa, nesse tipo de benefício oferecido é, além do fato de atrair e reter profissionais com talento em um mercado competitivo, também proporcionar que a motivação dos funcionários seja dirigida, concomitantemente, para os resultados da empresa a curto e a longo prazos (KIESO e WEYGANDT, 1998, p. 877 e ROBBINS, 2001, p. 199). Nessa visão, as ações e opções de ações alinham interesses, desencorajam comportamentos oportunistas, maximizam o bom comportamento e proporcionam altos níveis de desempenho (SANDERS, 2001, p. 488 e NIEMANN e SIMONS, 2003, p. 322).

Parte dessa motivação é revelada pelo fato de que os funcionários se enquadram, também, no papel de acionistas e, mantendo o direito de participação na empresa, mesmo se a deixarem no futuro, continuam com a posse dos títulos. Contudo, existem casos de planos de opções que apresentam restrições: a venda pelo funcionário, após a data de aquisição, deve obedecer a um certo período de carência (WESTON, CHUNG e SIU, 1998, p. 302 e ROSS, WESTERFIELD e JAFFE, 2002, p. 502).

Conforme comprovado pela popularidade apresentada, esse tipo de transação traz a possibilidade de altos ganhos, tanto para empregados quanto para as empresas. Para os empregados, sejam eles executivos ou não, a preferência por remuneração em ações e opções é detectada pela possibilidade que elas os tornem milionários, se a companhia obtiver sucesso nos seus negócios (KIESO e WEYGANDT, 1998, p. 853).

Para as empresas, o grande crescimento em popularidade de uso das opções de ações se deve à possibilidade de tomada de recursos a baixo custo para investimentos, ou para atividades de reestruturação, como a compra de outras empresas, diversificação de atividades e reversão de situações de prejuízos históricos duradouros e até de insolvência (CHEN, 2003, p. 942 e WESTON, CHUNG e SIU, 1998, p. 294).

Mas, apesar dos benefícios discriminados anteriormente, a volatilidade de preço das ações é de grande relevância, considerado o problema no uso das opções como incentivo. A sua ocorrência, influenciada por fatores externos ao controle da administração, afeta o preço das ações no mercado financeiro e o valor dos incentivos concedidos, abalando toda a estrutura de criação de motivação, proporcionada pela expectativa de ganhos futuros. Do mesmo modo que em toda transação que envolve valores mobiliários, o fator risco é inerente ao negócio, riscos esses nem sempre de controle pleno da gestão da organização (SILVEIRA, 2000, p. 51).

Também questiona-se se esses planos de incentivos proporcionam sempre a maximização do resultado da empresa. Trabalho de Bartov e Mohanram (2004) descreve vários estudos que mostram os planos de opções induzindo comportamentos oportunistas dos administradores, em detrimento do 
retorno dos acionistas e da empresa. Os mesmos confirmaram a ocorrência, através de um estudo que envolveu 1,2 mil empresas norte-americanas, entre 1992 e 2001. A conclusão foi que existe uma relação direta entre informações internas privilegiadas e a decisão de exercício das opções, em que elevados ganhos no exercício das opções foram facilitados pelo acesso a informações privativas das companhias.

Os autores reconhecem que, na teoria, planos de opções de ações reduzem custos de agência e melhor alinham interesses. Mas na prática, os administradores podem aumentar seus ganhos por meios não diretamente relacionados ao esforço exercido no alcance de resultados, comprometendo a eficácia do prêmio.

\section{MÉTODOS DE AVALIAÇÃO DAS OPÇÕES}

Quando se fala em avaliação de ativos para uso ou venda, obtidos por operações comerciais convencionais, a determinação do custo parece servir bem a essa função. No entanto, existem situações em que os ativos-objeto não são facilmente avaliáveis, representando um desafio do profissional de contabilidade, como nos mercados futuros e de opções.

A contabilidade permite a avaliação dos ativos de diversas maneiras. Geralmente, a descrição é baseada no custo histórico, mas podem ser utilizados fluxos de benefícios futuros líquidos trazidos a valor presente, custo histórico corrigido, custo de reposição, custo de reposição corrigido e valores de mercado. Além destes métodos de avaliação, existe o valor justo (fair value), definido como:

O montante pelo qual um ativo pode ser comprado ou vendido entre partes dispostas, por um preço que não seja forçado ou de liquidação ou que caracterize uma transação compulsória (SFAS n. 144, 2001, § 22 e Exposure Draft $\mathrm{n}$. 1201-100, 2004, § 4);

Numa visão jurídica, é uma combinação de bases de avaliação, determinadas pelas comissões e pelos tribunais para uma finalidade específica (HENDRIKSEN e VAN BREDA, 1999, p. 309);

Um montante que uma entidade espera receber, se alienar qualquer item na data financeira declarada. O montante da transação deve ser aceito pelas partes contratantes não relacionadas (ANTHONY, 2004, p. 25).
Uma característica fundamental da obtenção do valor justo em qualquer negócio consiste na suposição de que a organização é um empreendimento em funcionamento contínuo, sem qualquer intenção ou necessidade de liquidação, de restrição relevante de escala das suas operações ou de participação em transações em termos desfavoráveis (IASB apud IBRACON, 2002, p. 630).

A introdução do conceito de valor justo e a padronização do seu uso datam de 1992, quando o FASB publicou a norma SFAS n. 107 - Disclosures about fair value of financial instruments. Para a avaliação de ativos a valor justo, o FASB, o IASB, o IBRACON e a CVM, em consenso, informam que a melhor avaliação é feita via cotação de preços em mercados ativos, por serem as informações a esse respeito mais amplas, aceitas e disponíveis.

Mas, nem sempre, a cotação livre de mercado é facilmente encontrável. Neste caso, uma segunda alternativa de estimativa do valor justo deve ser baseada na melhor informação, considerando preços de ativos similares e resultados de técnicas de valoração (como valor presente dos esperados futuros fluxos de caixa, usando-se uma taxa de desconto e considerando-se o risco de desvios envolvidos). Outros métodos mais complexos de mensuração envolvem modelos de precificação de opções calcados em cálculos estatísticos, cálculos matriciais e modelos de ajuste de margem de opções.

Para quantificar a relação de custo/benefício de qualquer projeto e iniciativa, e a valoração de ativos derivativos, os modelos estatísticos de precificação são considerados a melhor forma. Pesquisas mostram que eles predizem bem os preços das opções negociadas no mercado (HOSKIN, 1997, p. 725), e, diante das incertezas podem ser ajustados para avaliar melhor a vida útil da opção (MARIS, MARIS e YANG, 2003, p. 670). Esses modelos reconhecem diversas variáveis, como o preço de exercício e expectativa de vida da ação, o preço corrente, a volatilidade esperada, a expectativa de dividendos futuros e a taxa corrente livre de riscos para a vida esperada da opção (ANTHONY 2004, p. 89).

Desde a publicação do modelo Black \& Scholes em 1972, as formas de cálculo estatísticas de precificação tornaram-se muito mais confiáveis, servindo de referência nas instituições financeiras e nos mercados de ações ao redor do mundo. Os mesmos modelos são considerados co-responsáveis por toda a transformação no ambiente financeiro ocorrida nas últimas quatro décadas, ainda representando um papel indispensável nos sistemas financeiros mundiais. (MERTON, 1998, p. 340 e 343). 


\section{NORMAS CONTÁBEIS SOBRE A DIVULGAČ̃̃O E MENSURAČ̃̃ DOS PLANOS DEE OPÇÕES DE AÇÕES}

Como em outras transações que envolvem a transferência de ativos, a contabilização de tais programas segue certas regras, e as principais são ditadas pelo FASB e pelo IASB. No Brasil, ainda, não existem regras específicas, existem entendimentos e recomendações de atendimento às mesmas normas internacionais. (NUNES, 2004, p. 111).

\subsection{Norma do FASB}

O Financial Accounting Standards Board (FASB) é o órgão que regulamenta as normas de contabilidade financeira, que se aplicam a todas as companhias de capital aberto e fechado, exceto entidades públicas, nos EUA. Nesse país, o início da preocupação com o tratamento contábil das opções de ações vem desde 1972, quando o Accounting Principles Board (APB), predecessor do FASB, emitiu a norma APB n. 25 - Accounting for Stock Issued to Employees. Essa norma especificava que o custo das opções na data da distribuição deveria ser medido por seu valor intrínseco, que consiste na simples diferença entre o valor de mercado corrente da ação e o preço de exercício da opção (SFAS n. $123,1995, \S 3^{\circ}$ ), considerado o ganho que poderia ser realizado se a opção fosse exercida imediatamente (SMITH e WALLACE, 1997, p. 484, PILBEAM, 1998, p. 327 e ARYA e SUN, 2004b, p. 305).

No início da década de 1980, o American Institute of Certified Public Accountants (AICPA) em assessoria à Securities and Exchange Commission (SEC) e a outros interessados ligados ao ramo empresarial começaram a rever a norma e propor alterações, culminando com a emissão, em 1995 da norma SFAS n. 123 - Accounting for Stock-Based Compensation. A norma SFAS n. 123 recomenda que o reconhecimento das opções de ações seja feito pelo valor justo, no qual as opções são mensuradas na data de concessão do incentivo, o cálculo é feito por um modelo de precificação (Black \& Scholes ou binomial) e esse valor reconhecido como despesa. Pelo texto, ainda há a permissão do uso da norma anterior e, em caso de a empresa continuar a adotar a norma antiga, em Nota Explicativa às Demonstrações Contábeis deverão ser expressos os valores e as diferenças no resultado quando do cálculo a valor justo (SFAS n. 123, 1995, § $5^{\circ} \mathrm{e}$ ANTHONY, 2004, p. 89).

Declarações críticas à atual norma existem e dizem respeito, principalmente, à expressão 'recomenda' e não 'obriga'. Conforme Bodie, Kaplan e
Merton (2003, p. 43-44) e Arya e Sun (2004b, p. 305) esse novo critério foi considerado, na verdade, um meio-termo que refletiu o grande lobby de empresários e políticos contrários ao registro compulsório, o qual predominou na discussão do tema no FASB. Os mesmos autores argumentaram que a economia norte-americana tinha crescido graças à adoção da prática anterior e que a norma alterada estancaria a geração de novos negócios no país no sentido de redução dos gastos com pesquisa, desenvolvimento e equipamentos, e que o emprego estaria ameaçado.

Informações importantes a respeito da adoção da atual prática e que merecem destaque são de Maris, Maris e Yang (2003, p. 672), que demonstram a aversão por parte das empresas ao reconhecimento do valor justo. Os autores, através da análise das demonstrações contábeis do exercício de 1996 de 93 empresas que possuíam opções de ações a funcionários, verificaram que em nenhuma delas houve o reconhecimento da despesa pelo valor justo, mas somente a divulgação pro forma em nota explicativa.

Outras informações partem de Balsam, Sami e Shahid (2003, p. 36) e de Bodie, Kaplan e Merton (2003, p. 44). Os primeiros, em um estudo com uma amostra de 242 empresas, encontraram diferenças muito significantes nos valores de despesa com remuneração de opções e o resultado da empresa após a adoção do valor justo para as mesmas opções. Os últimos, em ilustração do montante da diferença, citam que, se a AOL Time Warner tivesse, em 2001, registrado como despesa e a valor justo suas transações relacionadas com opções de ações a funcionários, o resultado reverteria de um lucro operacional divulgado em torno de US\$700 milhões para um prejuízo operacional de US\$1,7 bilhão.

Além da SFAS n. 123, em relação à remuneração baseada em ações, há a norma SFAS n. 148 - Accounting for Stock-Based Compensation - Transition and Disclosure: an amendment of FASB Statement $n .123$-, datada de 2002, que adiciona métodos alternativos a respeito da transição para o reconhecimento das operações a valor justo e na divulgação das transações.

Em março de 2004 o FASB, através do ofício 1102-100, emitiu uma proposta de alteração (Expositure Draft) da norma SFAS n. 123, intitulada Share-Based Payment: and amendment of FASB Statements n. 123 and 95, dando abertura para comentário público dos termos propostos de alteração. A proposta de alteração da norma atual do FASB está centrada nos seguintes tópicos:

- eliminar o método de contabilização descrito pela APB n. 25 e aceito pela SFAS n. 123; 
- $\quad$ as despesas de remuneração com opções devem ser devidamente reconhecidas;

- o valor da remuneração deve ser mensurado por seu valor justo, obtido ou pelo preço corrente de mercado de ativos iguais ou semelhantes, ou calculado por uma técnica de precificação conhecida e confiável;

- o montante da remuneração deve ser mensurado na data de concessão do direito e reconhecido durante o prazo de duração do serviço prestado; e

- caso haja modificação nos termos do incentivo após a concessão, as alterações devem ser reconhecidas e os novos montantes devem ser mensurados a valor justo (FASB, 2004).

$\mathrm{Na}$ emissão dessa proposta de alteração, o FASB entende que há quatro razões principais para a mudança da norma vigente:

- prover informação sobre assunto relevante para todos os interessados, de forma mais eficaz;

- aumentar a comparabilidade das informações obtidas e eliminar formas alternativas de contabilização;

- simplificar as normas contábeis vigentes; e

- buscar a convergência internacional, no tratamento dos incentivos em ações e opções (FASB, 2004).

Inicialmente, a expectativa de entrada em vigor das alterações seria a partir do início do ano de 2005. Recentemente a SEC, proporcionando mais tempo para as companhias se adaptarem às mudanças, prorrogou em mais 6 meses a data o início da vigência das alterações.

\subsection{Norma do IASB}

O Internacional Accounting Standards Board (IASB), sediado em Londres, Inglaterra, elabora e divulga normas adequadas e uniformes, contribuindo para a elaboração e divulgação das demonstrações contábeis, visando torná-las harmônicas internacionalmente.

Recentemente, o IASB criou, após um período de discussões, uma nova modalidade de norma, denominada International Financial Reporting Standards (IFRS), cujo intuito é o desenvolvimento por completo de um adequado sistema contábil internacional envolvendo as várias partes interessadas ao redor do mundo, incluindo contadores, analistas financeiros e outros interessados das normas financeiras, órgãos reguladores regionais, bolsas de valores, acadêmicos e a grande comunidade dos mercados financeiros (EPSTEIN e MIRZA, 2003, p. 7).

Em fevereiro de 2004, o IASB, enfatizando que os recentes eventos ocorridos no mundo corporativo (como os escândalos contábeis, as práticas de Governança Corporativa e o crescimento dos mercados em áreas antes inatingíveis) são de importância para o alcance de informações com alta qualidade (que provem alta neutralidade, transparência e comparabilidade das informações para auxiliar os gestores a tomar decisões econômicas), emitiu o International Financial Reporting Standard 2 (IFRS 2) - Share-based Payment, em relação à contabilização das concessões a funcionários em opções de ações, depois de um longo processo de discussão iniciado em julho de 2000.

Antes da emissão da IFRS 2, não havia um padrão internacional no reconhecimento e mensuração de pagamentos baseados em ações, forma que cresceu muito nos últimos anos. Em particular, a omissão do reconhecimento da despesa com pagamentos em ações com empregados tem sido considerada por investidores e outros interessados como causa de distorções econômicas e um problema de Governança Corporativa. A emissão da IFRS 2 satisfaz a lacuna existente nos padrões internacionais. Os requisitos da IFRS 2 substituem os requisitos divulgados na IAS n. 19 (IASB, 2004a, 2004b).

O objetivo da IFRS 2 é o de a organização especificar um reconhecimento financeiro quando se compromete com uma transação de pagamento baseado em ações. Em particular, a norma exige que a Companhia reflita em seu resultado e em sua posição financeira os efeitos das transações de pagamentos baseadas em ações, incluindo despesas associadas com a concessão de opções de ações a funcionários.

As principais exigências da IFRS 2 são:

- a Companhia deve reconhecer as transações em ações em suas demonstrações financeiras, incluindo transações com empregados;

- em princípio, nas transações em que haja o recebimento de bens ou serviços em troca da participação na Companhia, devem esses mesmos bens ou serviços ser mensurados pelo valor justo, extraído ou calculado de uma forma que reflita a realidade com maior aproximação;

- do mesmo modo, os serviços proporcionados pela empresa a seus funcionários e que lhes geram direitos de participação, 
devem ser mensurados a valor justo, na data da concessão;

- o valor justo das participações concedidas deve ser baseado no preço de mercado ou estimado usando-se uma técnica de precificação;

- caso os termos e condições da opção ou ação concedida sejam modificados, ou caso a concessão seja cancelada, recomprada ou substituída, a ocorrência deve ser divulgada;

- para os pagamentos baseados em ações, a entidade determinará se os fará pelas próprias ações, em espécie ou em outros instrumentos de participação na empresa;

- a norma prescreve várias exigências para uma ampla divulgação, dirigida para meIhor entendimento dos interessados nas demonstrações financeiras, que são:

- descrição da natureza e extensão dos existentes contratos de remuneração em ações;

- determinação do critério para avaliação do valor justo dos bens ou serviços recebidos, ou dos instrumentos de participação concedidos; e

- descrição das implicações que os pagamentos baseados em ações, no período relatado, geram no resultado econômico-financeiro da entidade (IASB, 2004b).

\subsection{Recomendações da CVM e do IBRACON}

A CVM emitiu, em janeiro de 2005, o OfícioCircular/CVM/SNC/SEP n. 01/2005, no qual, dentre vários outros assuntos relevantes, discrimina suas considerações sobre a matéria de remuneração por ações e opções.

O referido ofício descreve as opções de ações como uma modalidade de remuneração a empregados, informa sobre a prática contábil norte-americana, sobre a proposta de padronização internacional, (incluindo a forma de contabilização conforme a IFRS 2), sobre os métodos matemáticos de precificação e sobre os aspectos corporativos da aprovação do plano de opções.

$\mathrm{Na}$ contabilização dos planos de remuneração por ações e opções, o órgão recomenda à Companhia que a despesa oriunda desse tipo de incentivo seja reconhecida no período de sua ocorrência, e estimado pelo valor justo (ou seja, através de métodos de precificação adequados). Enquanto essa atitude não se transforma em uma exigência, é so- licitado ao menos que as empresas divulguem em Nota Explicativa às Demonstrações Financeiras Padronizadas qual seria o saldo do resultado do período e do patrimônio líquido, caso houvesse sido feita tal contabilização, do mesmo modo que consta na SFAS n. 123 (1995).

Na parte "divulgação em demonstrações contábeis e informações periódicas dos planos de opções", consta a aprovação da Norma de Procedimento de Contabilidade (NPC) n. 26/01 do IBRACON pelo parecer de orientação CVM n. 371/00, que estabelece que as companhias devem divulgar em Nota Explicativa às Demonstrações Contábeis e no formulário Informações Trimestrais (ITR) as seguintes informações relativas aos Planos de Opções, sempre comparativamente aos respectivos períodos anteriores:

- a existência de Planos de Opções, com a descrição de sua natureza e condições;

- a quantidade, descrição da natureza e condições e montante de opções outorgadas, exercidas e expiradas, se for o caso, detidas por cada grupo de beneficiários, incluindo o seu preço de exercício ou, se for o caso, a forma de cálculo para obtê-lo. A medida da elegibilidade dos beneficiários ao exercício do direito deve ser indicada;

- o percentual de diluição de participação a que, eventualmente, serão submetidos os atuais acionistas em caso de exercício de todas as opções a serem outorgadas;

- quanto às opções exercidas, descrição das ações entregues, em quantidade, classe e espécie, e o preço total e unitário de exercício relativamente a cada uma das classes e espécies e o respectivo valor de mercado nas respectivas datas;

- as datas ou períodos em que poderão ser exercidas opções pelos beneficiários e eventuais datas de expiração;

- descrição das eventuais negociações envolvendo ações em tesouraria para efetuar o resgate das opções, indicando a quantidade de ações, por classe e espécie, bem como o valor recebido pela Companhia e

- o efeito na Demonstração do Resultado do Exercício e no Patrimônio Líquido, caso essa contabilização tivesse sido feita (CVM, 2004).

Conforme o próprio ofício, entende-se que, num futuro próximo, seja implantada uma Instrução específica que trate da matéria, regulamentando de forma mais eficaz tanto o tratamento contábil quanto a divulgação das informações (NUNES, 2004, p. 119). 


\section{O ESTUDO EMPÍRICO: PROCEDIMENTOS METODOLÓGICOS}

A população consistiu de todas as companhias abertas listadas e ativas na CVM, empresas que dentre outras particularidades, são obrigadas a divulgar, periodicamente e de modo amplo, suas informações e resultados econômico-financeiros aos participantes do mercado de capitais, dentre outros interessados.

A amostra inicial escolhida para esta pesquisa foi composta por 35 empresas, representativas das companhias abertas que apresentam programas de captação de recursos no exterior via Depository Receipts (DR) níveis II e III. A relação das companhias elegíveis por esse critério foi capturada via informação da CVM na parte "Companhias Abertas - Programas de DR aprovados", da sua página na Internet <http://www.cvm.gov.br>, acessos em 04 de janeiro de 2004 e em 5 de maio de 2004.

A escolha de tal critério deveu-se ao fato de que essas empresas, no envio de suas informações contábeis à SEC e às Bolsas de Valores internacionais, devem atender às normas internacionais de Contabilidade (IAS-GAAP e/ou US-GAAP), dentre elas as relacionadas a operações com ações e opções a funcionários de um modo geral. Por isso, inicialmente foram buscadas as companhias que presumivelmente apresentam seus relatórios contábeis com nível informativo e de detalhes maior.

Dessa primeira amostra de companhias abertas foram pesquisadas as Notas Explicativas das DFP's enviadas à CVM, referentes ao exercício findo em 31 de dezembro de 2003, para detectar quais empresas apresentam no seu quadro de incentivos, os programas de opções de ações. As DFP's foram extraídas, via Internet, da CVM, durante o mês de maio de 2004. Como resultado, em 21 empresas não foram encontradas informações a respeito de tais programas de incentivos.

Das DFP's das 14 empresas restantes que apresentam planos de opções de ações a funcio- nários e que representam a amostra final, foram verificados o método de divulgação e os graus de abrangência e de detalhes das informações, em comparação com a Deliberação CVM n. 371/00 e com o Ofício-Circular/CVM/SNC/SEP n. 01/2004, quanto ao volume das informações que devem ser divulgadas.

Por fim, sobre as mesmas empresas da amostra final, foi feita uma nova análise com todas as Demonstrações Financeiras Consolidadas (DFC), tabuladas pelo formulário $20-\mathrm{F}$ e enviadas à SEC, verificando possíveis diferenças relevantes de tratamento que possam existir, entre a divulgação no Brasil e no exterior, especialmente quanto ao volume e qualidade das informações disponíveis para os investidores estrangeiros em comparação com as demonstrações fornecidas aos investidores locais. Os relatórios foram obtidos da página da SEC na Internet <http://www.sec.gov>, durante o mês de julho de 2004.

Em síntese, o estudo faz uma comparação entre o tratamento contábil conforme a regra brasileira e a norte-americana. A atual norma do IASB não foi objeto do estudo empírico. A mesma foi descrita, em enriquecimento do trabalho, devido à importância que possui, principalmente pela característica de exigir a forma de mensuração considerada mais correta, e pela tendência de tornar-se parâmetro, na busca da padronização internacional das regras contábeis.

\section{APRESENTAÇÃO DOS RESULTADOS}

De um modo geral, o tratamento que as companhias abertas brasileiras oferecem a planos de opções em ações não é uniforme (NUNES, 2004, p. 194-197). Nas informações constantes em Nota Explicativa às DFP's, praticamente nenhuma das empresas atende plenamente ao recomendado pelo IBRACON e pela CVM. O Quadro 1 expõe de forma resumida o que cada empresa apresenta em suas DFP's, em comparação ao que recomenda a CVM no ofício-circular CVM/SNC/SEP n. 01/2004.

\begin{tabular}{|c|c|c|c|c|c|c|c|}
\hline EMPRESA & 1 & 2 & 3 & 4 & 5 & 6 & 7 \\
\hline $\begin{array}{l}\text { BANCO ITAU HOLDING } \\
\text { FINANCEIRA S.A. }\end{array}$ & $\begin{array}{l}\text { sim, a executivos, } \\
\text { não informa o tipo }\end{array}$ & $\operatorname{sim}$ & não há & $\begin{array}{c}\text { informa a fórmula } \\
\text { de cálculo }\end{array}$ & $\operatorname{sim}$ & não há & não há \\
\hline BRASIL TELECOM S.A. & $\begin{array}{c}\text { sim, a administradores } \\
\text { e empregados, } \\
\text { ações preferenciais }\end{array}$ & $\operatorname{sim}$ & $\operatorname{sim}$ & $\begin{array}{c}\text { ainda não houve } \\
\text { o exercício }\end{array}$ & $\operatorname{sim}$ & não há & $\begin{array}{c}\text { somente } \\
\text { calculada a } \\
\text { despesa } \\
\text { pelo B\&S }\end{array}$ \\
\hline
\end{tabular}




\begin{tabular}{|c|c|c|c|c|c|c|c|}
\hline EMPRESA & 1 & 2 & 3 & 4 & 5 & 6 & 7 \\
\hline $\begin{array}{l}\text { CIA.BRASILEIRA } \\
\text { DE DISTRIBUIÇÃO }\end{array}$ & $\begin{array}{c}\text { sim, a administradores } \\
\text { e empregados, } \\
\text { ações preferenciais }\end{array}$ & $\operatorname{sim}$ & não há & $\operatorname{sim}$ & $\operatorname{sim}$ & não há & não há \\
\hline $\begin{array}{l}\text { COMPANHIA DE BEBIDAS } \\
\text { DAS AMÉRICAS-AMBEV }\end{array}$ & $\begin{array}{c}\text { sim, a funcionários } \\
\text { qualificados (executivos), } \\
\text { ações preferenciais } \\
\text { e ordinárias }\end{array}$ & $\operatorname{sim}$ & não há & $\operatorname{sim}$ & $\operatorname{sim}$ & $\begin{array}{c}\text { informa a } \\
\text { possibilidade }\end{array}$ & não há \\
\hline $\begin{array}{l}\text { EMBRAER EMP. } \\
\text { BRAS. AERON. S.A. }\end{array}$ & $\begin{array}{l}\text { sim, a empregados, } \\
\text { ações preferenciais }\end{array}$ & $\operatorname{sim}$ & não há & $\operatorname{sim}$ & $\operatorname{sim}$ & não há & $\begin{array}{c}\text { não há, } \\
\text { não é } \\
\text { considerada } \\
\text { despesa }\end{array}$ \\
\hline $\begin{array}{l}\text { EMBRATEL } \\
\text { PARTICIPAÇÕES S.A. }\end{array}$ & $\begin{array}{l}\text { sim, a diretores } \\
\text { e alguns empregados, } \\
\text { ações preferenciais }\end{array}$ & $\operatorname{sim}$ & não há & $\operatorname{sim}$ & $\operatorname{sim}$ & não há & $\operatorname{sim}$ \\
\hline GERDAU S.A. & $\begin{array}{c}\text { sim, a administradores, } \\
\text { empregados e prestadores } \\
\text { de serviços, ações } \\
\text { preferenciais }\end{array}$ & $\operatorname{sim}$ & $\operatorname{sim}$ & $\begin{array}{c}\text { ainda não } \\
\text { houve o exercício }\end{array}$ & $\operatorname{sim}$ & $\begin{array}{c}\text { informa a } \\
\text { possibilidade }\end{array}$ & não há \\
\hline $\begin{array}{l}\text { TELE CELULAR SUL } \\
\text { PARTICIPAÇÕES S.A. }\end{array}$ & $\begin{array}{l}\text { sim, a diretores } \\
\text { e executivos-chave, } \\
\text { ações preferenciais }\end{array}$ & $\operatorname{sim}$ & $\operatorname{sim}$ & $\begin{array}{c}\text { ainda não } \\
\text { houve o exercício }\end{array}$ & $\operatorname{sim}$ & $\begin{array}{l}\text { possibilidade } \\
\text { de futuros } \\
\text { aumentos } \\
\text { de capital }\end{array}$ & $\begin{array}{c}\text { aumento de } \\
\text { capital no } \\
\text { exercício } \\
\text { das opções }\end{array}$ \\
\hline $\begin{array}{l}\text { TELE NORDESTE } \\
\text { CELULAR PARTIC. S.A. }\end{array}$ & $\begin{array}{l}\text { sim, a dirigentes, } \\
\text { gerentes e principais } \\
\text { funcionários, } \\
\text { ações preferenciais }\end{array}$ & $\operatorname{sim}$ & $\operatorname{sim}$ & $\operatorname{sim}$ & $\operatorname{sim}$ & não há & $\begin{array}{c}\text { aumento de } \\
\text { capital no } \\
\text { exercício } \\
\text { das opções }\end{array}$ \\
\hline $\begin{array}{l}\text { TELE NORTE } \\
\text { CELULAR PARTIC. S.A }\end{array}$ & $\begin{array}{l}\text { sim, a executivos-chave } \\
\text { e outros empregados, } \\
\text { ações preferenciais } \\
\text { e ordinárias }\end{array}$ & $\operatorname{sim}$ & não há & $\begin{array}{l}\text { ainda não } \\
\text { houve o } \\
\text { exercício }\end{array}$ & $\operatorname{sim}$ & não há & não há \\
\hline $\begin{array}{l}\text { TELE NORTE } \\
\text { LESTE PARTIC. S.A. }\end{array}$ & $\begin{array}{l}\text { sim, a um grupo de } \\
\text { executivos, ações } \\
\text { preferenciais }\end{array}$ & $\operatorname{sim}$ & não há & $\begin{array}{l}\text { ainda não houve } \\
\text { o exercício }\end{array}$ & $\operatorname{sim}$ & não há & $\begin{array}{c}\text { provisiona a } \\
\text { diferença } \\
\text { entre o preço } \\
\text { de mercado } \\
\text { e o de } \\
\text { exercício }\end{array}$ \\
\hline $\begin{array}{l}\text { TELEMIG CELULAR } \\
\text { PARTIC. S.A. }\end{array}$ & $\begin{array}{l}\text { sim, a executivos-chave } \\
\text { e outros empregados, } \\
\text { ações preferenciais } \\
\text { e ordinárias }\end{array}$ & $\operatorname{sim}$ & não há & $\begin{array}{l}\text { ainda não houve } \\
\text { o exercício }\end{array}$ & $\operatorname{sim}$ & não há & não há \\
\hline $\begin{array}{l}\text { ULTRAPAR } \\
\text { PARTICIPAÇÕES S.A. }\end{array}$ & $\begin{array}{l}\text { sim, a administradores, } \\
\text { não informa o tipo }\end{array}$ & não há & sim, é zero & não há & $\operatorname{sim}$ & & $\begin{array}{c}\text { não há, valor } \\
\text { contabilizado } \\
\text { como } \\
\text { despesa e } \\
\text { amortizado } \\
\text { por } 10 \text { anos }\end{array}$ \\
\hline
\end{tabular}




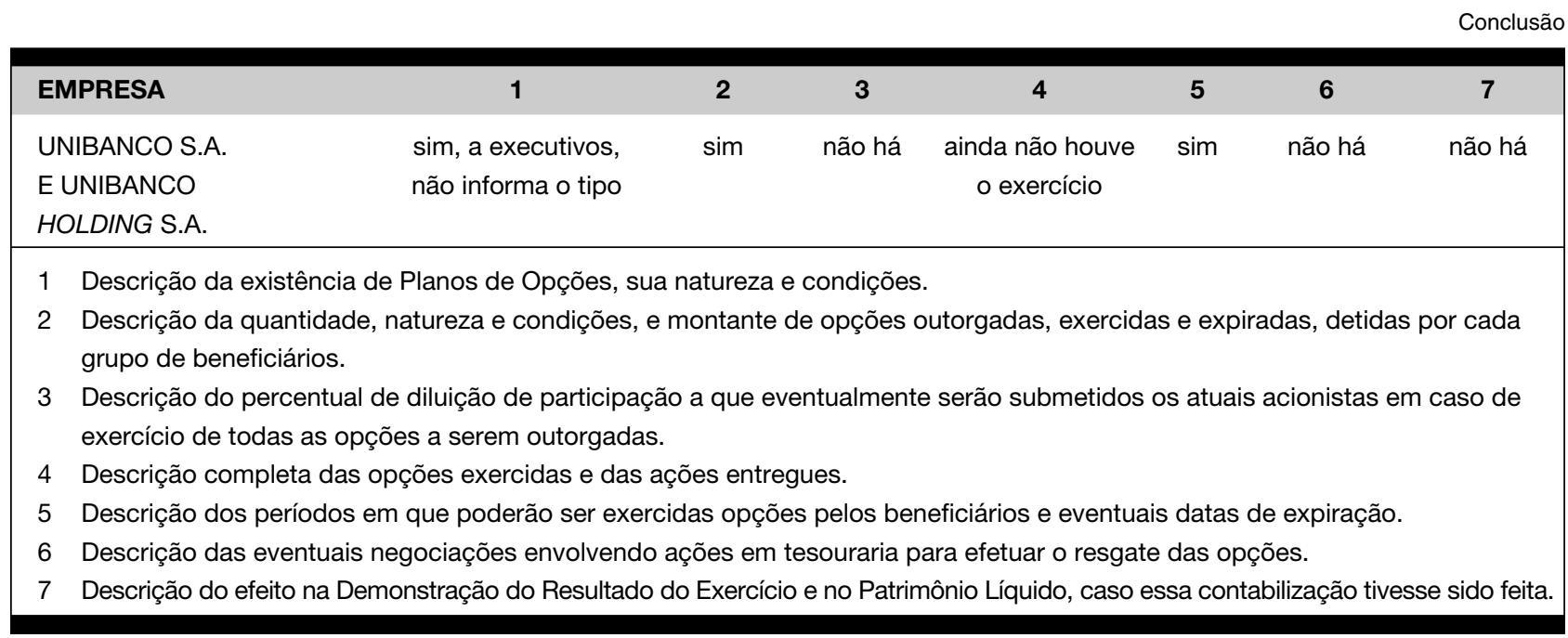

Fonte: Elaborado pelo autor, amparado pelas informações referentes aos planos de incentivos em opções de ações, constantes em Notas Explicativas às DFP's enviadas à CVM.

\section{Quadro 1 - Empresas do estudo: informações disponibilizadas pelas companhias, referente às opções de ações a empregados}

Pelo Quadro 1, percebe-se que em todas as empresas constam informações a respeito da existência de planos de outorga de opções de ações a empregados, sua natureza e condições. Do mesmo modo, em praticamente todas, os planos são formalizados via contrato entre a empresa e o funcionário, e a administração dos planos é feita por um comitê gestor, designado especificamente para tal atividade.

Ainda a respeito das condições, cada companhia de modo particular delimita os níveis hierárquicos beneficiados e as classes das ações disponibilizadas. A maioria concede somente ações preferenciais, exceção feita à AmBev e às empresas controladas pela Telpart (Tele Norte Celular e Telemig Celular), que também oferecem ações ordinárias.

Da mesma maneira, quase todas as empresas apresentam, em formato gráfico, informações quanto aos montantes de opções outorgadas que ainda estão dentro do prazo de carência, as exercidas e expiradas, bem como a movimentação de novas outorgas, e informações referentes aos prazos de carência e prazo para o direito de exercício.

Quanto ao percentual de diluição para os atuais acionistas com a emissão de novas ações aos funcionários, não são todas as empresas que divulgam o percentual máximo de novas ações que podem ser emitidas para honrar os compromissos com os empregados. Do mesmo modo, na divulgação quanto à emissão de novas ações ou ao uso de ações em tesouraria, tal informação é omitida por algumas empresas; em outras consta a possibilidade do uso de ambas as formas.

O ponto em que há a maior diferença de tratamento entre as empresas, dado o maior grau de subjetividade e arbitrariedade no tratamento do gasto e a conseqüente maior divergência com a recomendação do IBRACON e da CVM, consiste no reconhecimento contábil dos gastos relacionados à outorga das opções. No caso da Embraer, é explícito o não reconhecimento dos gastos como despesa; na Brasil Telecom há somente a informação do valor da despesa, calculada pelo método Black \& Scholes. A grande maioria das empresas omite informação quanto ao valor da despesa que envolve a concessão, calculado a valor justo, exceção única feita à Embratel, que informa o resultado ajustado, caso a precificação fosse feita por um modelo matemático. Outras empresas (casos da Tele Celular Sul e da Tele Nordeste Celular, que operam comercialmente sob a marca TIM) adotam o diferimento no reconhecimento do gasto, para a data de exercício das opões por parte dos empregados.

Situação peculiar é encontrada na Tele Norte Leste, que faz uma provisão do saldo composto pela diferença entre o preço corrente da ação e o preço de exercício na data da concessão. A despesa referente a essa provisão é considerada realizada quando da ocorrência do exercício das opções-objeto do plano e o saldo da provisão é calculado com base na média ponderada anual de opções que se tornam exercíveis. 
Em síntese, quanto à descrição dos efeitos da contabilização a valor justo de tais despesas, poucas se dispõem a apresentar os valores envolvidos, e nenhuma delas demonstra explicitamente o efeito da concessão e do exercício das opções no seu resultado operacional.
A segunda análise efetuada foi com base no formulário 20-F. Em resumo, das informações extraídas dos Relatórios 20-F e para melhor visualização das diferenças encontradas, foi confeccionado o Quadro 2 com os tópicos principais detectados.

\begin{tabular}{|c|c|c|c|c|c|}
\hline \multirow[b]{2}{*}{ EMPRESA } & \multirow[b]{2}{*}{$\begin{array}{l}\text { INFORMAÇÕES COMPLEMENTARES } \\
\text { ENCONTRADAS NO RELATÓRIO 20-F }\end{array}$} & \multicolumn{2}{|c|}{$\begin{array}{c}\text { CRITÉRIO } \\
\text { CONTÁBIL ADOTADO }\end{array}$} & \multicolumn{2}{|c|}{$\begin{array}{l}\text { MÉTODO DE PRECIFICAÇÃO } \\
\text { DE OPÇÕES ADOTADO }\end{array}$} \\
\hline & & APB n. 25 & SFAS n. 123 & $\begin{array}{l}\text { BLACK \& } \\
\text { SCHOLES }\end{array}$ & OUTRO \\
\hline $\begin{array}{l}\text { BANCO ITAU } \\
\text { HOLDING } \\
\text { FINANCEIRA S.A. }\end{array}$ & $\begin{array}{l}\text { Uso da emissão de novas ações ou de } \\
\text { ações em tesouraria. Adoção da prática } \\
\text { contábil de acordo com os US GAAP, } \\
\text { cálculo do resultado do exercício e do } \\
\text { lucro por ação, com as opções } \\
\text { calculadas pelo valor justo. São } \\
\text { apresentados os valores das variáveis } \\
\text { consideradas no cálculo do valor justo; } \\
\text { volume das opções in e out of the } \\
\text { money no final de } 2003 \text {. }\end{array}$ & $x$ & & & $x$ \\
\hline $\begin{array}{l}\text { BRASIL } \\
\text { TELECOM S.A. }\end{array}$ & $\begin{array}{l}\text { Adoção da prática contábil de acordo } \\
\text { com os US GAAP e cálculo do valor } \\
\text { justo das opções. São apresentados } \\
\text { os valores das variáveis consideradas } \\
\text { no cálculo do valor justo. }\end{array}$ & & $x$ & $x$ & \\
\hline $\begin{array}{l}\text { CIA. BRASILEIRA } \\
\text { DE DISTRIBUIÇÃO }\end{array}$ & $\begin{array}{l}\text { Adoção da prática contábil de acordo } \\
\text { com os US GAAP, cálculo do resultado } \\
\text { do exercício e do lucro por ação, com } \\
\text { as opções calculadas pelo valor justo. } \\
\text { São apresentados os valores das } \\
\text { variáveis consideradas no cálculo } \\
\text { do valor justo. }\end{array}$ & $x$ & & $x$ & \\
\hline $\begin{array}{l}\text { COMPANHIA } \\
\text { DE BEBIDAS } \\
\text { DAS AMÉRICAS- } \\
\text { AMBEV }\end{array}$ & $\begin{array}{l}\text { Uso da emissão de novas ações ou de } \\
\text { ações em tesouraria. Adoção da prática } \\
\text { contábil de acordo com os US GAAP, } \\
\text { cálculo do resultado do exercício e do } \\
\text { lucro por ação, com as opções } \\
\text { calculadas pelo valor justo. São } \\
\text { apresentados os valores das variáveis } \\
\text { consideradas no cálculo do valor justo. }\end{array}$ & $x$ & & $x$ & \\
\hline $\begin{array}{l}\text { EMBRAER } \\
\text { EMP. BRAS. } \\
\text { AERON. S.A. }\end{array}$ & $\begin{array}{l}\text { Adoção da prática contábil de acordo } \\
\text { com os US GAAP, cálculo do resultado } \\
\text { do exercício e do lucro por ação, com } \\
\text { as opções calculadas pelo valor justo. } \\
\text { São apresentados os valores das } \\
\text { variáveis consideradas no cálculo } \\
\text { do valor justo. }\end{array}$ & $x$ & & $x$ & \\
\hline
\end{tabular}




\begin{tabular}{|c|c|c|c|c|c|}
\hline \multirow[b]{2}{*}{ EMPRESA } & \multirow[b]{2}{*}{$\begin{array}{l}\text { INFORMAÇÕES COMPLEMENTARES } \\
\text { ENCONTRADAS NO RELATÓRIO 20-F }\end{array}$} & \multicolumn{2}{|c|}{$\begin{array}{c}\text { CRITÉRIO } \\
\text { CONTÁBIL ADOTADO }\end{array}$} & \multicolumn{2}{|c|}{$\begin{array}{l}\text { MÉTODO DE PRECIFICAÇÃO } \\
\text { DE OPÇÕES ADOTADO }\end{array}$} \\
\hline & & APB n. 25 & SFAS n. 123 & $\begin{array}{l}\text { BLACK \& } \\
\text { SCHOLES }\end{array}$ & OUTRO \\
\hline $\begin{array}{l}\text { EMBRATEL } \\
\text { PARTICIPAÇÕES S.A. }\end{array}$ & $\begin{array}{l}\text { Limite do volume de ações do plano } \\
\text { frente ao capital total; os níveis } \\
\text { hierárquicos elegíveis; quantidade dos } \\
\text { beneficiários do incentivo; a prática } \\
\text { contábil adotada de acordo com os } \\
\text { US GAAP; a movimentação das opções } \\
\text { do plano, discriminada concessão } \\
\text { a concessão. }\end{array}$ & $\mathrm{X}$ & & $x$ & \\
\hline GERDAU S.A. & $\begin{array}{l}\text { Adoção da prática contábil de acordo } \\
\text { com os US GAAP, cálculo do resultado } \\
\text { do exercício e do lucro por ação, com } \\
\text { as opções calculadas pelo valor justo. } \\
\text { São apresentados os valores das } \\
\text { variáveis consideradas no cálculo do } \\
\text { valor justo. }\end{array}$ & $\mathrm{X}$ & & $\mathrm{X}$ & \\
\hline $\begin{array}{l}\text { TELE CELULAR SUL } \\
\text { PARTICIPAÇÕES S.A. }\end{array}$ & $\begin{array}{l}\text { Adoção da prática contábil de acordo } \\
\text { com os US GAAP, cálculo do resultado } \\
\text { do exercício e do lucro por ação, com } \\
\text { as opções calculadas pelo valor justo. } \\
\text { São apresentados os valores das } \\
\text { variáveis consideradas no cálculo } \\
\text { do valor justo. }\end{array}$ & $\mathrm{X}$ & & $x$ & \\
\hline $\begin{array}{l}\text { TELE NORDESTE } \\
\text { CELULAR } \\
\text { PARTIC. S.A. }\end{array}$ & $\begin{array}{l}\text { Adoção da prática contábil de acordo } \\
\text { com os US GAAP, cálculo do resultado } \\
\text { do exercício e do lucro por ação, com } \\
\text { as opções calculadas pelo valor justo. } \\
\text { São apresentados os valores das } \\
\text { variáveis consideradas no cálculo } \\
\text { do valor justo. }\end{array}$ & $x$ & & $\mathrm{X}$ & \\
\hline $\begin{array}{l}\text { TELE NORTE } \\
\text { CELULAR } \\
\text { PARTIC. S.A }\end{array}$ & $\begin{array}{l}\text { Adoção da prática contábil de acordo } \\
\text { com os US GAAP, cálculo do resultado } \\
\text { do exercício e do lucro por ação, com } \\
\text { as opções calculadas pelo valor justo. } \\
\text { São apresentados os valores das } \\
\text { variáveis consideradas no cálculo } \\
\text { do valor justo. }\end{array}$ & $\mathrm{X}$ & & $x$ & \\
\hline $\begin{array}{l}\text { TELE NORTE } \\
\text { LESTE } \\
\text { PARTIC. S.A. }\end{array}$ & $\begin{array}{l}\text { Discriminação da prática contábil } \\
\text { adotada de acordo com os US GAAP } \\
\text { e do índice de correção adotado para } \\
\text { o preço de exercício. Como a empresa } \\
\text { considera que o incentivo pode ser } \\
\text { pago em espécie, a empresa faz uma } \\
\text { provisão do saldo, não reconhecendo } \\
\text { de modo pro forma. }\end{array}$ & $x$ & & & $x$ \\
\hline
\end{tabular}


Conclusão

\begin{tabular}{|c|c|c|c|c|c|}
\hline \multirow[b]{2}{*}{ EMPRESA } & \multirow[b]{2}{*}{$\begin{array}{l}\text { INFORMAÇÕES COMPLEMENTARES } \\
\text { ENCONTRADAS NO RELATÓRIO 20-F }\end{array}$} & \multicolumn{2}{|c|}{$\begin{array}{c}\text { CRITÉRIO } \\
\text { CONTÁBIL ADOTADO }\end{array}$} & \multicolumn{2}{|c|}{$\begin{array}{l}\text { MÉTODO DE PRECIFICAÇÃO } \\
\text { DE OPÇÕES ADOTADO }\end{array}$} \\
\hline & & APB n. 25 & SFAS n. 123 & $\begin{array}{l}\text { BLACK \& } \\
\text { SCHOLES }\end{array}$ & OUTRO \\
\hline $\begin{array}{l}\text { TELEMIG } \\
\text { CELULAR } \\
\text { PARTIC. S.A. }\end{array}$ & $\begin{array}{l}\text { Adoção da prática contábil de acordo } \\
\text { com os US GAAP, cálculo do resultado } \\
\text { do exercício e do lucro por ação, com } \\
\text { as opções calculadas pelo valor justo. } \\
\text { São apresentados os valores das } \\
\text { variáveis consideradas no cálculo } \\
\text { do valor justo. }\end{array}$ & $X$ & & $X$ & \\
\hline $\begin{array}{l}\text { ULTRAPAR } \\
\text { PARTICIPAÇÕES S.A. }\end{array}$ & $\begin{array}{l}\text { Volume de funcionários beneficiados } \\
\text { pelo plano, adoção da prática contábil } \\
\text { de acordo com os US GAAP. Não } \\
\text { consta divulgação pro forma desde } \\
\text { que os resultados do uso do método } \\
\text { do valor justo para contabilizar } \\
\text { os gastos com a remuneração sejam } \\
\text { iguais ao método do valor intrínseco. }\end{array}$ & $x$ & & somente usu & de ações \\
\hline $\begin{array}{l}\text { UNIBANCO S.A. e } \\
\text { UNIBANCO } \\
\text { HOLDING S.A. }\end{array}$ & $\begin{array}{l}\text { Data da aprovação do plano em AGE, } \\
\text { volume de beneficiários e montante da } \\
\text { despesa reconhecida como } \\
\text { remuneração. São apresentadas a } \\
\text { prática contábil adotada de acordo } \\
\text { os US GAAP e a movimentação do } \\
\text { plano ano a ano. }\end{array}$ & & $X$ & $X$ & \\
\hline
\end{tabular}

Fonte: Elaborado pelo autor, amparado pelas informações disponibilizadas pelos Relatórios 20-F fornecidos pelas empresas consultadas.

\section{Quadro 2 - Informações adicionais encontradas nos Relatórios 20-F enviados a SEC}

Com base no Quadro 2, algumas considerações podem ser feitas. Os valores de movimentação das opções, constantes de forma gráfica e enviados à SEC, são os mesmos enviados à CVM. A principal diferença entre os relatórios está no maior grau de detalhes nos enviados à SEC, quanto à descrição da operacionalização dos planos e informações e a respeito da movimentação dos saldos. Há preocupação de todas as companhias em atender às disposições contábeis constantes no SFAS n. 123, informando o valor do resultado em caso de a contabilização da despesa com remuneração ser a valor justo.

Ainda sobre tratamento contábil dos valores envolvidos, as empresas se expressam sobre a não exigência no Brasil, de registro das operações com opções de ações a funcionários como despesa de remuneração. Por essa ocorrência, pode ser explicada a diversidade do grau de detalhes apresentado entre as companhias, nas DFP's enviadas à CVM, umas apresentando os saldos e a movimentação em formato gráfico, outras somente discriminando os termos gerais e os saldos de encerramento (NUNES, 2004, p. 210).

Ainda não há uma mudança de mentalidade para a efetiva contabilização das opções a valor justo (somente a Brasil Telecom e o Unibanco apresentam seus resultados em atendimento ao recomendado pela SFAS n. 123). Quase todas as companhias apresentam os resultados a valor justo através de divulgação pro forma, sendo a efetiva contabilização feita com base no valor intrínseco disposto pela APB n. 25 e aceito pela SFAS n. 123.

Outra constatação: em quase todas as companhias, o método de precificação usado para cálculo do valor justo das opções é o Black \& Scholes, considerado o que estima melhor o valor das opções. A exceção é o Itaú, que adota o método binomial. A Tele Norte Leste faz o reconhecimento do dispêndio, calculado pelo valor intrínseco, através de uma provisão para quando do exercício das opções, e 
informa que não há necessidade de divulgação pro forma. Tal método difere o reconhecimento da despesa com remuneração variável para a data do efetivo pagamento.

Na Ultrapar, a concessão somente do usufruto temporário de ações em tesouraria, dispensa cálculos de precificação de opções. O valor da despesa envolvido na remuneração é igual ao valor à vista das ações-objeto incluindo encargos, cálculo feito em novembro de 2003, e essa despesa será amor- tizada de forma linear por dez anos. A empresa não considerou diferença entre o valor da despesa e o valor justo das ações no fechamento do exercício, situação que poderá ocorrer nos próximos anos.

A respeito dos valores envolvidos, o tratamento das opções como despesa e a valor justo, em quase todos os casos, reduz o resultado operacional e o lucro por ação (NUNES, 2004, p. 211). O Quadro 3 revela as variações apresentadas no Lucro Líquido, devido à divulgação pro forma exigida pela SFAS n. 123.

\begin{tabular}{|c|c|c|c|c|c|c|c|c|c|}
\hline \multicolumn{10}{|c|}{ Resultados expressos em milhares de Reais } \\
\hline \multicolumn{5}{|c|}{ Ambev } & \multicolumn{5}{|c|}{ Embratel } \\
\hline & 2003 & 2002 & 2001 & Total & & 2003 & 2002 & 2001 & Total \\
\hline 1 & 1.689 .400 & 1.642 .200 & 840.100 & 4.171 .700 & 1 & 382.083 & $(677.860)$ & $(464.250)$ & $(760.027)$ \\
\hline 2 & 1.664 .000 & 1.619 .100 & 822.900 & 4.106 .000 & 2 & 372.824 & $(681.285)$ & $(471.914)$ & $(780.375)$ \\
\hline 3 & $-1,50 \%$ & $-1,41 \%$ & $-2,05 \%$ & $-1,57 \%$ & 3 & $-2,42 \%$ & $-0,51 \%$ & $-1,65 \%$ & $-2,68 \%$ \\
\hline \multicolumn{5}{|c|}{ Itaú } & \multicolumn{5}{|c|}{ Tele Celular Sul } \\
\hline & 2003 & 2002 & 2001 & Total & & 2003 & 2002 & 2001 & Total \\
\hline 1 & 3.281 .000 & 2.828 .000 & 1.844 .000 & 7.953 .000 & 1 & 112.014 & 87.992 & 48.111 & 248.117 \\
\hline 2 & 3.391 .000 & 2.783 .000 & 1.831 .000 & 8.005 .000 & 2 & 110.415 & 86.393 & 47.045 & 243.853 \\
\hline 3 & $3,35 \%$ & $-1,59 \%$ & $-0,70 \%$ & $0,65 \%$ & 3 & $-1,43 \%$ & $-1,82 \%$ & $-2,22 \%$ & $-1,72 \%$ \\
\hline \multicolumn{5}{|c|}{ Tele Nordeste Celular } & \multicolumn{5}{|c|}{ Tele Norte Celular } \\
\hline & 2003 & 2002 & 2001 & Total & & 2003 & 2002 & 2001 & Total \\
\hline 1 & 222.876 & 102.466 & 61.365 & 386.707 & 1 & 35.732 & $(44.450)$ & (11.795) & (20.513) \\
\hline 2 & 221.227 & 101.391 & 60.649 & 383.267 & 2 & 35.369 & (44.734) & $(11.881)$ & (21.246) \\
\hline 3 & $-0,74 \%$ & $-1,05 \%$ & $-1,17 \%$ & $-0,89 \%$ & 3 & $-1,02 \%$ & $-0,64 \%$ & $-0,73 \%$ & $-3,57 \%$ \\
\hline \multicolumn{5}{|c|}{ Telemig Celular } & & & & & \\
\hline & 2003 & 2002 & 2001 & Total & & & & & \\
\hline 1 & 215.583 & 22.240 & 87.214 & 325.037 & & & & & \\
\hline 2 & 214.579 & 22.002 & 87.148 & 323.729 & & & & & \\
\hline 3 & $-0,47 \%$ & $-1,07 \%$ & $-0,08 \%$ & $-0,40 \%$ & & & & & \\
\hline \multicolumn{10}{|c|}{ Resultados expressos em milhares de Dólares norte-americanos } \\
\hline \multicolumn{5}{|c|}{ CBD } & \multicolumn{5}{|c|}{ Embraer } \\
\hline & 2003 & 2002 & 2001 & Total & & 2003 & 2002 & 2001 & Total \\
\hline 1 & 112.909 & 60.477 & 100.671 & 274.057 & 1 & 136.044 & 222.592 & 328.440 & 687.076 \\
\hline 2 & 110.473 & 57.207 & 96.136 & 263.816 & 2 & 136.044 & 222.592 & 318.151 & 676.787 \\
\hline 3 & $-2,16 \%$ & $-5,41 \%$ & $-4,50 \%$ & $-3,74 \%$ & 3 & $0,00 \%$ & $0,00 \%$ & $-3,13 \%$ & $-1,50 \%$ \\
\hline
\end{tabular}




\begin{tabular}{|c|c|c|c|c|c|c|}
\hline \multicolumn{7}{|c|}{ Resultados expressos em milhares de Dólares norte-americanos } \\
\hline \multicolumn{5}{|c|}{ Gerdau } & & \\
\hline & 2003 & 2002 & 2001 & Total & & \multirow{4}{*}{$\begin{array}{l}\text { Lucro Líquido } \\
\text { Lucro Líquido ajustado pro forma } \\
\text { Variação \% (Lucro Líquido / Lucro Líquido } \\
\text { ajustado pro forma) }\end{array}$} \\
\hline 1 & 510.164 & 231.827 & 167.353 & 909.344 & \multirow{3}{*}{3} & \\
\hline 2 & 509.732 & 231.682 & 167.220 & 908.634 & & \\
\hline 3 & $-0,08 \%$ & $-0,06 \%$ & $-0,08 \%$ & $-0,08 \%$ & & \\
\hline
\end{tabular}

Fonte: Elaborado pelo autor, amparado pelas informações disponibilizadas pelos Relatórios 20-F fornecidos pelas empresas consultadas.

\section{Quadro 3 - Variação no resultado líquido, ocasionada pela divulgação pro forma exigida pela SFAS n. 123}

Pela observação do Quadro 3, em alguns casos, as diferenças são percentualmente pequenas, mas em outros são relevantes, como na CBD, em que a variação foi de até $5,4 \%$ em 2002. Para as empresas que apresentaram o resultado líquido em Reais (AmBev, Embratel, Itaú, Tele Celular Sul, Tele Nordeste Celular, Tele Norte Celular e Telemig Celular), a diferença foi de $1,45 \%$, em média; nas empresas que divulgaram o resultado em Dólares norte-americanos (casos da Embraer, CBD e Gerdau), o resultado líquido diminuiu em 1,77\%, em média. Exemplos de valores podem ser dados pela AmBev, com redução do resultado por volta de $\mathrm{R} \$$ 65,7 milhões nos últimos três anos e na Embraer, com queda de quase US\$10,3 milhões no Lucro Líquido, no mesmo período. São valores expressivos, em se tratando de incentivos oferecidos a um seleto número de funcionários, apesar de percentualmente representarem pouco no resultado divulgado (1,57\% e $1,5 \%$, respectivamente).

\section{CONCLUSÃO}

A partir das informações obtidas, nota-se que os planos de incentivos baseados na outorga de opções de ações representam um tipo de remuneração variável que trata de premiar o funcionário pelo bom serviço prestado, proporcionando a ele elevados ganhos. Seu uso ainda beneficia a empresa, pois o funcionário tende a ficar mais motivado e trabalhar com a preocupação de acionista, tratando de decidir não somente em benefício próprio, mas em benefício da organização como um todo.

A respeito da contabilização dos eventos que envolvem desde a concessão até o exercício das opções e compra das ações-objeto, existem regras específicas, e essas são motivo de discussões por grandes entidades regulamentadoras, pois ainda não houve um consenso sobre a melhor forma de avaliar, mensurar e divulgar as informações inerentes a esses planos.

Declarações atuais do IASB tendem a padronizar universalmente o tratamento de opções a empregados, principalmente agora, após a emissão da IFRS 2. O FASB, em concordância com as regras vigentes do IASB, caminha para alteração da atual norma.

A CVM, em consenso de opinião com os órgãos estrangeiros, possui tentativas em criar uma Instrução que padronize o tratamento da remuneração por opções. Uma delas ocorreu em 2002, quando foi elaborado um draft e enviado para discussão em audiência pública. Por abordar pontos controversos, como a mensuração do valor justo da despesa, o projeto não foi levado adiante. Em contatos recentes com a entidade, a informação é de que não mais houve abertura de audiência pública. Como meio alternativo visando melhorar e padronizar a informação contábil, desde 2004 é adotada a publicação do Oficio-Circular, em que há a recomendação de apresentação de informações mais detalhadas.

Coerente com as considerações apresentadas, no estudo empírico, os relatórios enviados à CVM e ao mercado de capitais nacional apresentam informações a respeito dos incentivos em opções, mas não seguem um padrão de informações básicas, apresentadas no último parecer de orientação emitido pela CVM. Em vários casos, é explícita a menção de que, a despesa com a concessão de opções não é reconhecida. Já nas informações disponibilizadas nos relatórios 20-F enviados à SEC e ao mercado de capitais internacional, há a padronização exigida pela SFAS n. 123, considerando o ajuste do resultado e do lucro por ação, caso a contabilização a valor justo fosse feita. 
Amparado pelas considerações apresentadas, acredita-se que a forma que mais aproxima os valores envolvendo opções da realidade, é a mensuração a valor justo (NUNES, 2004, p. 221). A grande maioria das empresas do estudo não faz a contabilização desses ativos considerando cálculos de precificação, situação que tende a mudar com a emissão recente de novas regras e de outras que estão a caminho, que pretendem aprimorar o grau informativo da real situação econômico-financeira das companhias.

Os mais importantes órgãos normativos contábeis, discriminados neste artigo, continuam seus estudos e discussões a fim de alcançarem um consenso a respeito da solução mais eficaz para o problema de avaliação, mensuração e divulgação dos valores envolvidos, nas transações relacionadas com ações e opções de ações a funcionários. Outros estudos acadêmicos, que demonstrem as distorções apresentadas no uso do método atual e que proponham aprimoramento nos atuais métodos de contabilização e divulgação, serão bem-vindos, tornando-se muito importantes para o alcance desse consenso.

\section{REFERÊNCIAS BIBLIOGRÁFICAS}

ANTHONY, R. N.. Rethinking the rules of financial accounting New York: McGraw-Hill, 2004.

; GOVINDARAJAN, Vijay. Sistemas de controle gerencial. São Paulo: Atlas, 2002.

ARYA, Avinash; SUN, Huey-Lian. Impact of deregulation on CEO compensation: the case of electic utilities. American Business Review. West Haven, v. 22, n. 1, p. 27-33, Jan. 2004.

Stock option repricing: heads I win, tails you lose. Journal of Business Ethics. Dordrecht, v. 50, n. 4, p. 297312, Apr. 2004.

BALSAM, Steven; SAMI, Heibatollah; SHAHID, Abdus. Valuation implications of disclosures mandated by FAS 123: accounting for stock-based compensation. American Business Review. West Haven, v. 21, n. 1, p. 30-37, Jan. 2003.

BARTOV, Eli; MOHANRAM, Partha. Private information, earnings manipulations, and executive stock-option exercises. The Accounting Review. Sarasota, v. 79, n. 4, p. 889-920, Oct. 2004.

BODIE, Zvi; KAPLAN, Robert S.; MERTON, Robert C.. Pela última vez: opções de ações são despesa. Harvard Business Review. Boston, v. 81, n. 3, p. 43-51, mar. 2003.

BOLSA DE VALORES DE SÃO PAULO. Disponível em: <http:// www.bovespa.com.br>. Acesso em: $01 \mathrm{dez} .2003$.

CATANACH, Shelley C. Rhoades. Dot.com or dot.bom? The umpleasant tax surprise of stock options in a volatile market Issues in Accounting Education. Sarasota, v. 18, n. 4, p. 385-395, Nov. 2003.

CHEN, Chih-Ying. Investment opportunities and the relation between equity value and employees' bonus. Journal of business Finance \& Accounting. Oxford, v. 30, n. 7/8, p. 941-973, Sep./ Oct. 2003.

COMISSÃO DE VALORES MOBILIÁRIOS. Disponível em: <http:// www.cvm.gov.br>. Acesso em: 06 set. 2003.

Ofício-Circular/CVM/SNC/SEP $n^{\circ}$ 01/2004, de 19 de janeiro de 2004. Disponível em: <http://www.cvm.gov.br> Acesso em: 08 abr. 2004
EPSTEIN, Barry J.; MIRZA, Abbas Ali. IAS 2003: Interpretation and aplications of international accounting standards. Hoboken: John Wiley \& Sons, 2003.

FINANCIAL ACCOUNTING STANDARDS BOARD. Disponível em: <http://www.fasb.org >. Acesso em: 25 abr. 2004.

Exposure Draft $n^{\circ} 1201-100$, de Jun. 2004. Fair Value Measurements. Disponível em: <http://www.fasb.org/draft/ ed fair_value_measurements.pdf>. Acesso em: 16 set. 2004.

Statement of financial accounting standards $n^{\circ} 123$, de Oct. 1995. Accounting of stock-based compensation. Disponível em: <http://www.fasb.org/pdf/fas123.pdf>. Acesso em: $14 \mathrm{dez}$. 2003.

Statement of financial accounting standards $n^{\circ} 144$, de Aug. 2001. Accounting for the impairment of disposal of longlived assets. Disponível em: <http://www.fasb.org/pdf/fas 144 . pdf $>$. Acesso em: 04 abr. 2004.

HENDRIKSEN, Eldon S.; VAN BREDA, Michael F.. Teoria da Contabilidade. São Paulo: Atlas, 1999.

HOSKIN, Robert E.. Financial accounting - a user perspective. 2nd ed. New York: John Wiley \& Sons, 1997.

INSTITUTO DOS AUDITORES INDEPENDENTES DO BRASIL. Normas internacionais de contabilidade 2001. São Paulo: IBRACON, 2002.

INTERNATIONAL ACCOUNTING STARDARDS BOARD. About us. Disponível em: <http://www.iasb.org/about/iasb.asp >. Acesso em: 08 maio 2004

IASB issues Standard on Share-based Payment. Feb 19, 2004. Disponível em: <http://www.iasb.org/news/index.asp? showPageContent=no\&xml=10_84_25_19022004.htm>. Acesso em: 08 maio 2004

JOHNSON, C. H.. Stock and Stock Option Compensation: A Bad Idea. Canadian Tax Journal. Toronto, v. 51, n. 1, p. 1259, 2003. Disponível em: <http://proquest.umi.com/pqdweb? inde $\mathrm{x}=19$ \&did $=000000435067391 \& \mathrm{SrchMode}=3 \& \mathrm{sid}=1 \& \mathrm{Fmt}=3 \& \mathrm{VI}$ nst $=$ PROD $\&$ VType $=P Q D \& R Q T=309 \& V$ Name $=P Q D \& T S=108217$ 3265\&clientld=22460 >. Acesso em: 13 abr. 2004. 
KIESO, Donald E.; WEYGANDT, Jerry J.. Intermediate Accounting. 9th ed. New York: John Wiley \& Sons, 1998.

KRAIZBERG, Elli; TZINER, Aharon; WEISBERG, Jacob. Employee stock options: are they indeed superior to other incentive compensation schemes? Journal of Business and Psychology. New York, v. 16, n. 3, p. 383-390, Spring 2002.

MARIS, Brian A.; MARIS, Jo-Mae; YANG, Tyler T.. The effect of exercise date uncertainty on employee stock option value. Journal of Business Finance \& Accounting. Oxford, v. 30, n. 5/6, p. 669-697, June/July 2003.

MERTON, Robert C.. Applications of option-pricing theory: twentyfive years later. The American Economic Review. Nashville, v. 88, n. 3, p. 323-349, June, 1998.

NIEMANN, Rainer; SIMONS, Dirk. Costs, benefits, and taxinduced distortions of stock option plans. Schmalenbach Business Review. Duesseldorf, v. 55, n. 4, p. 321-341, Oct. 2003.

NUNES, Alexssander de A.. Práticas contábeis utilizadas pelas companhias abertas brasileiras no reconhecimento e divulgação em suas demonstrações contábeis, de informações relativas a planos de incentivos a funcionários, associados a cessão de ações e opções de ações. 2004. 223 f. Dissertação (Mestrado em Ciências Contábeis) - Universidade Federal do Rio de Janeiro, Rio de Janeiro.

PILBEAM, Keith. Finance \& financial markets. Houndmills: Macmillan Press, 1998. 390p.
ROBBINS, Stephen P.. Organizational behavior. 9th ed. Upper Saddle River: Prentice Hall, 2001.

ROSS, Stephen A.; WESTERFIELD, Randolph W.; JAFFE, Jeffrey F.. Administração financeira. 2. ed. São Paulo: Atlas, 2002.

SANDERS, Wm. Gerard. Behavioral responses of CEOs to stock ownership and stock option pay. Academy of Management Journal. Briarcliff Manor, v. 44, n. 3, p. 477-492, June, 2001.

SECURITIES AND EXCHANGE COMMISSION. Disponível em: <http://www.sec.gov>. Acesso em: 05 jul. 2003.

SILVEIRA, Mauro. Algemas de ouro. Você s.a. São Paulo, ano 3, n. 27 , p. $48-54$, set. 2000.

SMITH; Kimberly J.; WALLACE, Wanda A.. Instructional case: Chrysler's historical compensation and governance arrangements. Issues in Accounting Education. Sarasota, v. 12, n. 2, p. 457-495, Fall. 1997.

SUL, Wonsik; KIM, Soo-Jung. Are stock option plans utilized effectively for ventures?: evidence from korean venture firms. Journal of Financial Management \& Analysis. Mumbai, v. 16, n. 2, p. 37-48, July/Dec. 2003.

WESTON, J. Fred; CHUNG, Kwang S.; SIU, Juan A.. Takeovers, restructuring, and corporate governance. 2 nd ed. Upper Saddle River: Prentice Hall, 1998.

NOTA:

Endereço dos autores:

Univ. Fed. do Rio de Janeiro

Av. Brigadeiro Trompowsky s/n

Ilha do Fundão - RJ

21941-590 